Check for updates

Cite this: RSC Adv., 2019, 9, 4771

\title{
Poly(ethylene oxide)/Ag ions and nanoparticles/1- hexyl-3-methylimidazolium tetrafluoroborate composite membranes with long-term stability for olefin/paraffin separation
}

\begin{abstract}
Hyunsik Jeon ${ }^{a}$ and Sang Wook Kang (D) *ab
A poly(ethylene oxide)(PEO)/AgBF $4 / 1$-hexyl-3-methylimidazolium tetrafluoroborate $\left(\mathrm{HMIM}^{+} \mathrm{BF}_{4}{ }^{-}\right)$ composite membrane that exhibits long-term stability was prepared for olefin/paraffin separation. The membrane was prepared by simply adding $\mathrm{AgBF}_{4}$ and $\mathrm{HMIM}^{+} \mathrm{BF}_{4}{ }^{-}$to a solution of PEO. Long-term stability testing showed that the separation performance of the membrane is maintained for $\approx 100 \mathrm{~h}$ owing to the Ag NPs formed in the membrane, which are olefin carriers, being stabilized by $\mathrm{HMIM}^{+} \mathrm{BF}_{4}{ }^{-}$. In terms of separation performance, the $\mathrm{PEO} / \mathrm{AgBF}_{4} / \mathrm{HMIM}^{+} \mathrm{BF}_{4}{ }^{-}$composite membrane exhibited a propylene/propane selectivity of 11.8 and a mixed-gas permeance of $11.3 \mathrm{GPU}$. We also investigated the factors that determine separation performance by comparison with a $\mathrm{PEO} / \mathrm{AgBF}_{4} / 1$-butyl-3methylimidazolium tetrafluoroborate $\left(\mathrm{BMIM}^{+} \mathrm{BF}_{4}{ }^{-}\right)$composite membrane. The $\mathrm{PEO} / \mathrm{AgBF}_{4} / \mathrm{HMIM}^{+} \mathrm{BF}_{4}{ }^{-}$ composite membrane was characterized by scanning electron microscopy, FT-IR spectroscopy, ultraviolet-visible spectroscopy, thermogravimetric analysis, and Raman spectroscopy.
\end{abstract}

Received 9th November 2018 Accepted 26th January 2019

DOI: $10.1039 / \mathrm{c} 8 \mathrm{ra} 09274 \mathrm{e}$

rsc.li/rsc-advances transport membranes, which are selectively permeable to only specific substances, have been attracting research attention. ${ }^{\mathbf{1 0}}$ Facilitated transport, which exploits the concentration gradient of solutes generated by the reversible reactions of compounds in membrane with specific solutes, promotes the transport of these solutes. $^{\mathbf{1 6}}$ For example, a dimethylpropylenediamine ethoxyacetate ([DMAPAH][EOAc] ) membrane for $\mathrm{CO}_{2} / \mathrm{N}_{2}$ separation using diamine-monocarboxylate protic ionic liquids (PILs) as carriers has been reported to show a selectivity of 151 and a $\mathrm{CO}_{2}$ permeability of 3028 barrer. ${ }^{17}$ In addition, an arginine salt-chitosan membrane using the amino group in the arginine salt as a carrier was reported to show a selectivity of 144 and a $\mathrm{CO}_{2}$ permeability of 1500 barrer in $\mathrm{CO}_{2} / \mathrm{H}_{2}$ separation. ${ }^{18}$ Recently, it has been reported that PEBAX-1657, which is a permeable polymer that contains Ag ions as olefin carriers, has a propylene/propane selectivity of 8.8 and a permeability of 22.5 GPU. ${ }^{19}$ In general, Ag salts are used as olefin carriers, but Ag ions generated from $\mathrm{Ag}$ salts are easily reduced and consequently lose carrier activity. ${ }^{\mathbf{2 0 - 2 2}}$ Thus, attempts have been made to partially polarize the surface of $\mathrm{Ag}$ NPs so that they react reversibly with olefins. ${ }^{21}$ However, Ag NPs acting as olefin carriers have a drawback in that the permeability of the host membrane is lowered due to the barrier action that occurs when the Ag NPs aggregate to form larger NPs. ${ }^{22}$ In addition, membranes using ZIF and MOF have also been reported. ${ }^{23-32}$ Recently, we fabricated a poly(ethylene oxide)(PEO)/AgBF $4 / 1$ butyl-3-methylimidazolium tetrafluoroborate $\left(\mathrm{BMIM}^{+} \mathrm{BF}_{4}{ }^{-}\right)$ composite membrane in an attempt to restrict the size of the $\mathrm{Ag}$
${ }^{a}$ Department of Chemistry, Sangmyung University, Seoul 03016, Republic of Korea. E-mail: swkang@smu.ac.kr; Fax:+82 22287 5362; Tel: +82 222875362

${ }^{b}$ Department of Chemistry and Energy Engineering, Sangmyung University, Seoul 03016, Republic of Korea 
NPs formed therein. We reasoned that $\mathrm{BMIM}^{+} \mathrm{BF}_{4}{ }^{-}$would stabilize the smaller nascent Ag NPs, inhibiting their aggregation and thus maintaining membrane permeability. The average size of the particles formed in the composite membrane after the long-term test was $4.55 \mathrm{~nm}$. The prepared $\mathrm{PEO} / \mathrm{AgBF}_{4} /$ $\mathrm{BMIM}^{+} \mathrm{BF}_{4}^{-}$composite membrane exhibited a propylene/ propane selectivity of $\approx 15$ and a permeability of 12 GPU. ${ }^{33}$ In the current study, we assessed whether stability could be maintained using ionic liquids other than $\mathrm{BMIM}^{+} \mathrm{BF}_{4}{ }^{-}$in order to investigate the factors that contribute to the long-term stability of such membranes. 1-Hexyl-3-methylimidazolium tetrafluoroborate $\left(\mathrm{HMIM}^{+} \mathrm{BF}_{4}{ }^{-}\right)$was used as the new ionic liquid to investigate the effect of the carbon chain length of ionic liquids, and compared with $\mathrm{BMIM}^{+} \mathrm{BF}_{4}{ }^{-}$in viewpoint of both stabilizing the nanoparticles and separation performance.

\section{Experimental}

\subsection{Materials}

Acetonitrile (99.8\%) was purchased from Aldrich Chemical Co. and PEO $\left(M_{\mathrm{w}} 6 \times 10^{5} \mathrm{~g} \mathrm{~mol}^{-1}\right)$ was purchased from ACROS Co. Silver tetrafluoroborate $\left(\mathrm{AgBF}_{4}, 98 \%\right)$ was purchased from Tokyo Chemical Industry Co., and $\mathrm{HMIM}^{+} \mathrm{BF}_{4}{ }^{-}$was purchased from C-TRI. The microporous polysulfone support was provided by Toray Chemical Inc., Korea. All the initial solvents and materials were used without further purification.

\subsection{Characterization}

Scanning electron microscopy (SEM) images were obtained using JEOL JSM-5600LV. The weight loss of the complex was measured using thermogravimetric analysis (TGA, TGA Q50, TA Instruments) under $\mathrm{N}_{2}$ flow. The ultraviolet-visible (UV-Vis) absorption spectra were recorded using a Beckman Coulter Life Sciences DU 730 Life Science UV-Vis spectrophotometer with $1 \mathrm{~nm}$ resolution. The IR measurements were performed on a VERTEX 70 FT-IR spectrometer; 16-32 scans were signal averaged with a resolution of $8 \mathrm{~cm}^{-1}$. Raman spectra of neat $\mathrm{HMIM}^{+} \mathrm{BF}_{4}{ }^{-}$were obtained using a BRUKER RAM II instrument at a resolution of $0.5 \mathrm{~cm}^{-1}$.

\subsection{Membrane preparation}

The $\mathrm{PEO} / \mathrm{AgBF}_{4} / \mathrm{HMIM}^{+} \mathrm{BF}_{4}{ }^{-}$complex membrane was prepared by adding $\mathrm{AgBF}_{4}$ and $\mathrm{HMIM}^{+} \mathrm{BF}_{4}{ }^{-}$to a PEO polymer solution and vacuum drying. The $5 \mathrm{wt} \%$ PEO polymer solution was prepared by dissolving PEO in water/acetonitrile $(9: 10 \mathrm{w} / \mathrm{w})$. $\mathrm{AgBF}_{4}$ was added to the prepared $\mathrm{PEO}$ polymer solution at $1: 1$ molar ratio, and $\mathrm{HMIM}^{+} \mathrm{BF}_{4}{ }^{-}$was added at different mole ratios. The solution was coated onto polysulfone microporous membrane supports using an RK Control Coater (Model K202, Control Coater RK Print-Coat Instruments Ltd., UK). The longterm stability of the composite membrane prepared at a composition of $1 / 1 / 0.052$ and vacuum dried for $24 \mathrm{~h}$ showed the best performance.

\subsection{Gas separation performance}

The permeation test was performed by permeating the $\mathrm{PEO} /$ $\mathrm{AgBF}_{4} / \mathrm{HMIM}^{+} \mathrm{BF}_{4}{ }^{-}$composite membrane with a propylene/ propane mixed gas $(1: 1 \mathrm{v} / \mathrm{v})$. The permeance was measured using a bubble flow meter and the selectivity was assessed by gas chromatography (YoungLin $6500 \mathrm{GC}$ system). The flow rate of the mixed gas was controlled by a mass flow controller (MFC). The unit of gas permeance is GPU $\left(1 \mathrm{GPU}=1 \times 10^{-6} \mathrm{~cm}^{3}\right.$ (STP)/ $\left.\left(\mathrm{cm}^{2} \mathrm{~s} \mathrm{cmHg}\right)\right)$.

\section{Results and discussion}

\subsection{SEM images}

Fig. 1 shows a cross-section of the $\mathrm{PEO} / \mathrm{AgBF}_{4} / \mathrm{HMIM}^{+} \mathrm{BF}_{4}^{-}$ composite membrane. The membrane was prepared by coating $\mathrm{PEO} / \mathrm{AgBF}_{4} / \mathrm{HMIM}^{+} \mathrm{BF}_{4}{ }^{-}$solution onto a polysulfone support and vacuum drying for $24 \mathrm{~h}$. The sponge-like polysulfone support was well coated with $\mathrm{PEO} / \mathrm{AgBF}_{4} / \mathrm{HMIM}^{+} \mathrm{BF}_{4}{ }^{-}$. The thickness of the resultant layer was $\approx 4.5 \mu \mathrm{m}$.

\subsection{UV-Vis absorption spectra}

The stabilizing effect of $\mathrm{HMIM}^{+} \mathrm{BF}_{4}{ }^{-}$on the $\mathrm{Ag}$ NPs generated in $\mathrm{PEO} / \mathrm{AgBF}_{4} / \mathrm{HMIM}^{+} \mathrm{BF}_{4}{ }^{-}$solution was investigated by UV-Vis spectroscopy. $\mathrm{PEO} / \mathrm{AgBF}_{4} / \mathrm{HMIM}^{+} \mathrm{BF}_{4}{ }^{-}$solutions were heated at $70{ }^{\circ} \mathrm{C}$ for $10,20,30$, and $60 \mathrm{~min}$. The peak for $\mathrm{Ag}$ NPs is typically observed at $420 \mathrm{~nm} .^{21}$ Thus, a peak at about $420 \mathrm{~nm}$ indicates the formation of $\mathrm{Ag}$ NPs, while the intensity of the peak represents the concentration of Ag NPs formed. When the $\mathrm{PEO} / \mathrm{AgBF}_{4} / \mathrm{HMIM}^{+} \mathrm{BF}_{4}{ }^{-}$solution is heated for $10 \mathrm{~min}$, a peak is observed at 403-423 $\mathrm{nm}$. Upon heating for $20 \mathrm{~min}$, a slight peak shift is observed. Upon heating for 30 and $60 \mathrm{~min}$, no further peak shifting is observed, but the peak intensity increases. These results indicate that Ag NPs are stabilized by $\mathrm{HMIM}^{+} \mathrm{BF}_{4}{ }^{-}$. This is because the surface of the Ag NPs is partially polarized by $\mathrm{HMIM}^{+} \mathrm{BF}_{4}{ }^{-}$, thus inhibiting aggregation and particle growth. As a result, after a heating time of $20 \mathrm{~min}$, only small Ag NPs are formed. Moreover, the spectrum presents a symmetric peak, indicating that monodisperse AgNPs were formed in the $\mathrm{PEO} / \mathrm{AgBF}_{4} / \mathrm{HMIM}^{+} \mathrm{BF}_{4}{ }^{-}$solution. From these

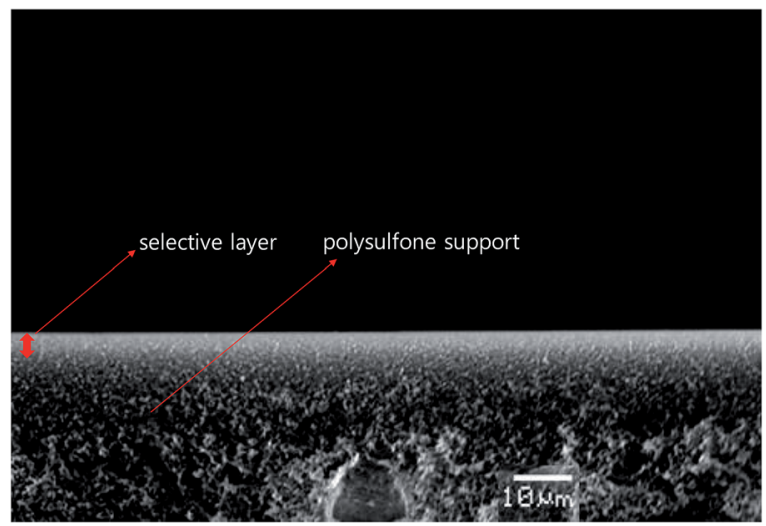

Fig. 1 Cross-sectional SEM image of $\mathrm{PEO} / \mathrm{AgBF}_{4} / \mathrm{HMIM}^{+} \mathrm{BF}_{4}$ composite membrane. 
results, it was confirmed the effect of stabilizing the NPs by ILs since the relatively narrow peak was observed at UV-Vis spectroscopy (Fig. 2).

\section{3. $\quad$ FT-IR spectra}

FT-IR was measured to confirm the coordination interactions of ether group and $\mathrm{Ag}$ ion of PEO. Fig. 3 showed the ether group stretching band peak of $\mathrm{PEO} / \mathrm{AgBF}_{4} / \mathrm{HMIM}^{+} \mathrm{BF}_{4}{ }^{-}$complex. Generally, the ether group stretching band peak of neat PEO was known to be observed at $1082 \mathrm{~cm}^{-1}$. When $\mathrm{AgBF}_{4}$ was incorporated into PEO, the peak shifted to about $1070 \mathrm{~cm}^{-1}$. This was attributable to the interaction between the $\mathrm{Ag}$ ion and oxygen in ether group resulting in weaker $\mathrm{C}-\mathrm{O}$ bonds. ${ }^{34}$ Furthermore, when $\mathrm{HMIM}^{+} \mathrm{BF}_{4}{ }^{-}$was additionally inserted into $\mathrm{PEO} / \mathrm{AgBF}_{4}$ complex, the peak shifted to $1014 \mathrm{~cm}^{-1}$. This could be explained by the interaction of $\mathrm{HMIM}^{+}$with $\mathrm{BF}_{4}{ }^{-}$of $\mathrm{AgBF}_{4}$, resulting in the weakened bond between $\mathrm{Ag}$ ions and $\mathrm{BF}_{4}{ }^{-}$, and the strong interaction between $\mathrm{Ag}^{+}$and oxygen in ether group. Therefore, the $\mathrm{C}-\mathrm{O}$ bond became weakened and free $\mathrm{BF}_{4}{ }^{-}$of $\mathrm{HMIM}^{+} \mathrm{BF}_{4}{ }^{-}$could stabilize the generated Ag NPs.

\subsection{Separation performance for propylene/propane mixtures}

Fig. 4 shows the propylene/propane separation performance of the $\mathrm{PEO} / \mathrm{AgBF}_{4} / \mathrm{HMIM}^{+} \mathrm{BF}_{4}{ }^{-}$composite membrane. The

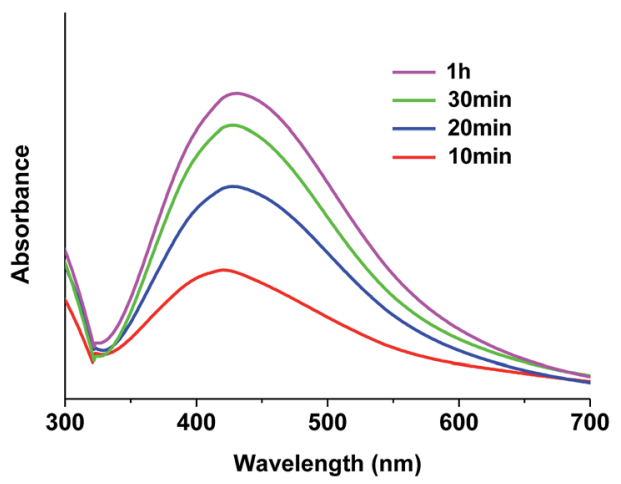

Fig. 2 UV-Vis absorption spectra of $\mathrm{PEO} / \mathrm{AgBF}_{4} / \mathrm{HMIM}^{+} \mathrm{BF}_{4}{ }^{-}$solution with heating time.

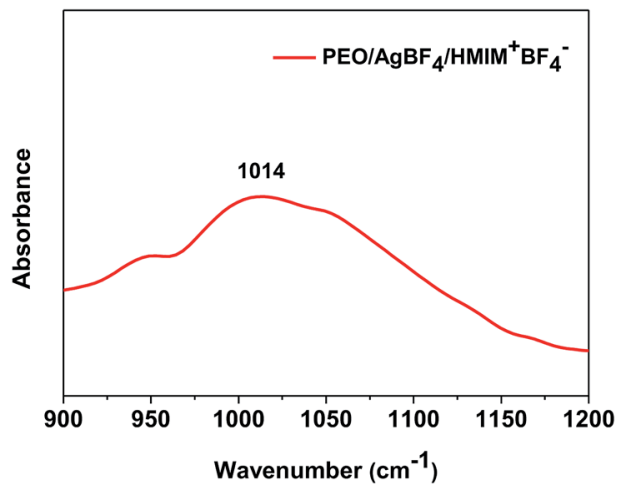

Fig. 3 FT-IR spectra of $\mathrm{PEO} / \mathrm{AgBF}_{4} / \mathrm{HMIM}^{+} \mathrm{BF}_{4}{ }^{-}$complex.

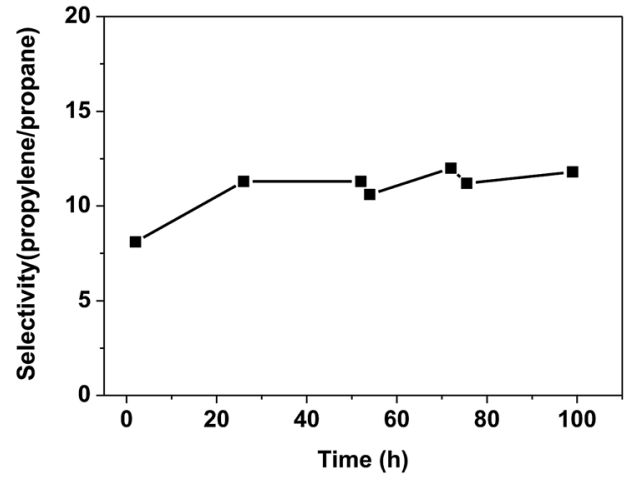

(a)

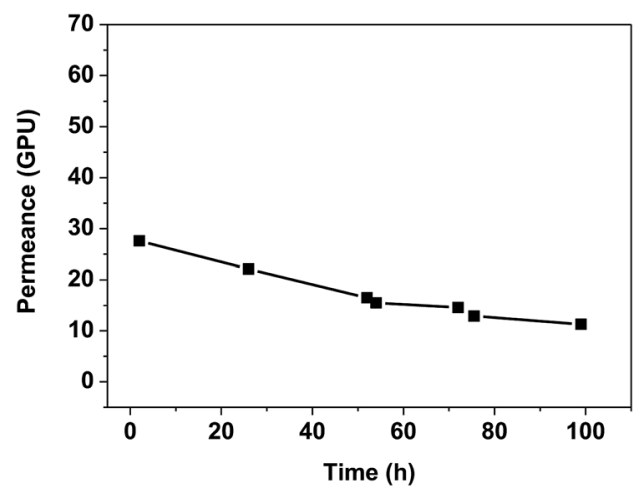

(b)

Fig. 4 Separation performance of $\mathrm{PEO} / \mathrm{AgBF}_{4} / \mathrm{HMIM}^{+} \mathrm{BF}_{4}{ }^{-}$composite membrane. (a) Selectivity for propylene/propane mixture, and (b) mixed gas permeance.

selectivity is initially 8.1 and then increases slightly after $20 \mathrm{~h}$, remaining at $\approx 11.8$ for $100 \mathrm{~h}$. The permeance decreases with the evaporation of the solvent remaining in the membrane, but the rate of decrease slows after $50 \mathrm{~h}$ and the permeance remains at 11.3 GPU at $100 \mathrm{~h}$. This separation performance is due to the stabilization of the $\mathrm{Ag}$ NPs by $\mathrm{HMIM}^{+} \mathrm{BF}_{4}{ }^{-}$. The $\mathrm{Ag}$ NPs formed in the $\mathrm{PEO} / \mathrm{AgBF}_{4} / \mathrm{HMIM}^{+} \mathrm{BF}_{4}{ }^{-}$composite membrane are stabilized by $\mathrm{HMIM}^{+} \mathrm{BF}_{4}{ }^{-}$, inhibiting their aggregation. Smaller $\mathrm{Ag}$ NPs act as more efficient olefin carriers; thus, the propylene/ propane separation performance of the $\mathrm{PEO} / \mathrm{AgBF}_{4} /$ $\mathrm{HMIM}^{+} \mathrm{BF}_{4}{ }^{-}$composite membrane is maintained because the NPs do not aggregate as shown in Scheme 1.

\subsection{Thermogravimetric analysis}

The thermal stabilities of neat PEO, PEO/AgBF 4 , and PEO/ $\mathrm{AgBF}_{4} / \mathrm{HMIM}^{+} \mathrm{BF}_{4}{ }^{-}$membranes were measured by TGA. Fig. 5 shows the weight loss for each membrane at temperatures ranging from room temperature to $700{ }^{\circ} \mathrm{C}$. For the neat PEO membrane, a large weight loss occurs between 380 and $450{ }^{\circ} \mathrm{C}$ owing to the degradation of the polymer. The $\mathrm{PEO} / \mathrm{AgBF}_{4}$ and $\mathrm{PEO} / \mathrm{AgBF}_{4} / \mathrm{HMIM}^{+} \mathrm{BF}_{4}{ }^{-}$membranes exhibit weight losses at lower temperatures owing to the interaction between the added $\mathrm{AgBF}_{4}$ and the $\mathrm{PEO}$ chains. Furthermore, when $\mathrm{HMIM}^{+} \mathrm{BF}_{4}{ }^{-}$was added to $\mathrm{PEO} / \mathrm{AgBF}_{4}$, there was significant change in the curve 


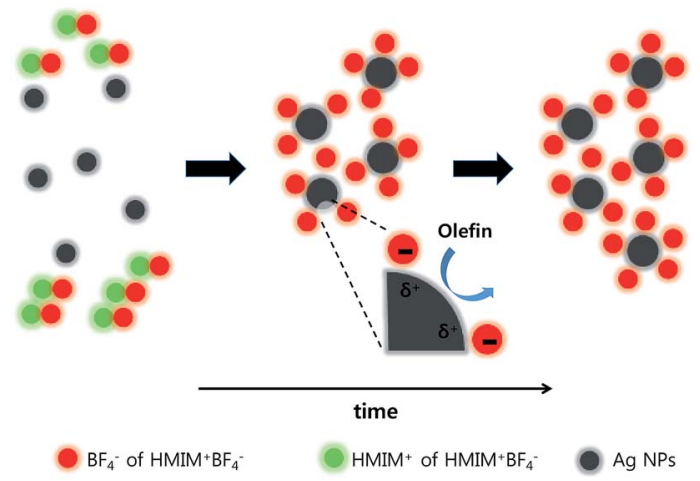

Scheme 1 Ag NPs formation in $\mathrm{PEO} / \mathrm{AgBF}_{4} / \mathrm{HMIM}^{+} \mathrm{BF}_{4}{ }^{-}$composite membrane upon heating.

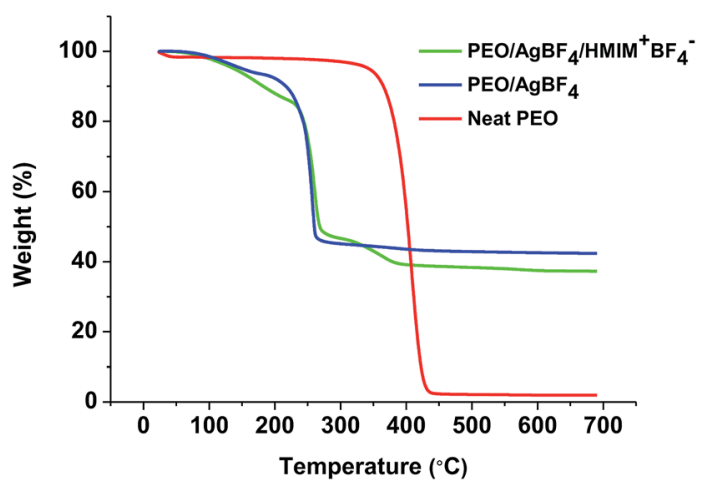

Fig. 5 TGA curves for neat PEO (red), $\mathrm{PEO} / \mathrm{AgBF}_{4}$ (blue), and $\mathrm{PEO} /$ $\mathrm{AgBF}_{4} / \mathrm{HMIM}^{+} \mathrm{BF}_{4}{ }^{-}$(green) complex.

compared to that for $\mathrm{PEO} / \mathrm{AgBF}_{4}$, indicating that plasticizing effect is produced by the added $\mathrm{HMIM}^{+} \mathrm{BF}_{4}{ }^{-}$. This result was same from that for the $\mathrm{PEO} / \mathrm{AgBF}_{4} / \mathrm{BMIM}^{+} \mathrm{BF}_{4}{ }^{-}$composite membrane previously reported. The TGA of $\mathrm{PEO} / \mathrm{AgBF}_{4} /$ $\mathrm{BMIM}^{+} \mathrm{BF}_{4}^{-}$composite membrane was measured in the presence of polysulfone support, but was plasticized like the $\mathrm{PEO} /$ $\mathrm{AgBF}_{4} / \mathrm{HMIM}^{+} \mathrm{BF}_{4}{ }^{-}$membrane. ${ }^{33}$ Due to this plasticizing effect, the permeance does not decrease due to the generation of nanoparticles but the permeance remains constant.

Raman spectra were obtained to investigate the state of $\mathrm{BF}_{4}{ }^{-}$ in $\mathrm{HMIM}^{+} \mathrm{BF}_{4}{ }^{-}$. In general, the free ion, ion pair, and ion aggregate stretching bands of $\mathrm{BF}_{4}^{-}$are observed at 765, 770, and $774 \mathrm{~cm}^{-1}$, respectively. ${ }^{35}$ In previous studies, the $\mathrm{BF}_{4}{ }^{-}$ionic constituents of neat $\mathrm{BMIM}^{+} \mathrm{BF}_{4}{ }^{-}$were found to exist mostly as ion pairs with some ion aggregates. ${ }^{36}$ However, the $\mathrm{BF}_{4}{ }^{-}$ionic constituents of neat $\mathrm{HMIM}^{+} \mathrm{BF}_{4}{ }^{-}$are mainly observed to be free ions $\left(740 \mathrm{~cm}^{-1}\right)$, as shown in Fig. 6 . In general, the more of the ionic liquid that exists as free ions, the better its ability to stabilize Ag NPs. Thus, $\mathrm{HMIM}^{+} \mathrm{BF}_{4}{ }^{-}$stabilizes $\mathrm{Ag}$ NPs more than $\mathrm{BMIM}^{+} \mathrm{BF}_{4}{ }^{-}$, but $\mathrm{HMIM}^{+} \mathrm{BF}_{4}{ }^{-}$has low molecular mobility because of its large molecular size and thus initially does not stabilize Ag NPs. Therefore, slightly larger Ag NPs are initially formed in $\mathrm{HMIM}^{+} \mathrm{BF}_{4}{ }^{-}$. In addition, $\mathrm{HMIM}^{+} \mathrm{BF}_{4}{ }^{-}$molecules do not exhibit good mobility even when they penetrate the

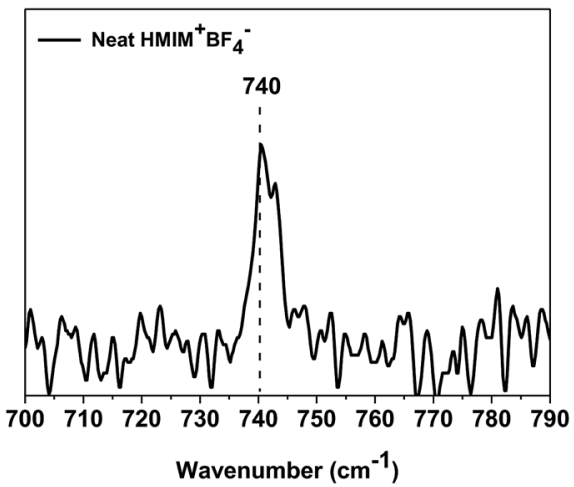

Fig. 6 Raman spectrum of neat $\mathrm{HMIM}^{+} \mathrm{BF}_{4}{ }^{-}$.

Table 1 Propylene/propane selectivity and mixed-gas permeance of $\mathrm{PEO} / \mathrm{AgBF}_{4} / \mathrm{HMIM}^{+} \mathrm{BF}_{4}{ }^{-}$composite membranes after conversion of $\mathrm{Ag}$ ions to $\mathrm{Ag}$ nanoparticles

\begin{tabular}{lll}
\hline & $\begin{array}{l}\text { Selectivity } \\
\text { (propylene/ } \\
\text { propane) }\end{array}$ & $\begin{array}{l}\text { Permeance } \\
\text { (GPU) }\end{array}$ \\
\hline $\begin{array}{l}\mathrm{PEO} / \mathrm{AgBF} \\
\text { membrane }\end{array}$ & 11.8 & 11.3 \\
\end{tabular}

polymer, because of their large size. This is consistent with the fact that the plasticizing effect does not occur.

Therefore, the $\mathrm{PEO} / \mathrm{AgBF}{ }_{4} / \mathrm{HMIM}^{+} \mathrm{BF}_{4}{ }^{-}$composite membrane exhibits poorer performance than that of the $\mathrm{PEO} /$ $\mathrm{AgBF}_{4} / \mathrm{BMIM}^{+} \mathrm{BF}_{4}{ }^{-}$composite membrane owing to the increased size of the initially formed Ag NPs and the low mobility of $\mathrm{HMIM}^{+} \mathrm{BF}_{4}{ }^{-}$in the polymer. The separation performances of the $\mathrm{PEO} / \mathrm{AgBF}_{4} / \mathrm{HMIM}^{+} \mathrm{BF}_{4}{ }^{-}$composite membranes were compared in Table 1.

\section{Conclusions}

We succeeded in preparing for the $\mathrm{PEO} / \mathrm{AgBF}_{4} / \mathrm{HMIM}^{+} \mathrm{BF}_{4}{ }^{-}$ composite membrane and confirmed the long-term stability of propylene/propane selectivity of $\mathbf{1 1 . 8}$ and permeance of $\mathbf{1 1 . 3}$ GPU for more than $100 \mathrm{~h}$. The long-term stability is owing to the stabilization of the Ag NPs by ionic liquid $\mathrm{HMIM}^{+} \mathrm{BF}_{4}{ }^{-}$. $\mathrm{HMIM}^{+} \mathrm{BF}_{4}^{-}$could partially polarize the surfaces of $\mathrm{Ag}$ NPs generated under separation process, resulting in the formation of olefin carriers. We also compared the performance of the $\mathrm{PEO} / \mathrm{AgBF}_{4} / \mathrm{BMIM}^{+} \mathrm{BF}_{4}{ }^{-}$composite membrane with that of the current membrane to help elucidate the factors that determine separation performance in such membranes. As a result, the effect of the carbon chain length of ionic liquids was investigated, and both butyl in $\mathrm{BMIM}^{+} \mathrm{BF}_{4}{ }^{-}$and hexyl groups in $\mathrm{HMIM}^{+} \mathrm{BF}_{4}{ }^{-}$were found to be effective in stabilizing the nanoparticles. However, by identifying other ionic liquids with longer carbon chains such as 1-methyl-3-octylimidazolium tetrafluoroborate in the future, we intend to identify main factors 
in the design of long-term stable facilitated olefin transport membranes.

\section{Conflicts of interest}

There are no conflicts to declare.

\section{Acknowledgements}

This work was supported by the Basic Science Research Program (2017R1D1A1B03032583) through the National Research Foundation of Korea (NRF), funded by the Ministry of Science, ICT, and Future Planning. This study was also funded by Korea Environment Industry \& Technology Institute (KEITI) as "Technology Program for establishing biocide safety management". (RE201805019).

\section{Notes and references}

1 C. H. Park, J. H. Lee, J. P. Jung and J. H. Kim, J. Membr. Sci., 2017, 533, 48-56.

2 W. J. Koros, AIChE J., 2004, 50, 2326-2334.

3 S. Jeong and S. W. Kang, Chem. Eng. J., 2017, 327, 500-504.

4 W. R. True, Oil Gas J., 2012, 110, 78-84.

5 R. B. Eldridge, Ind. Eng. Chem. Res., 1993, 32, 2208-2212.

6 R. L. Burns and W. J. Koros, J. Membr. Sci., 2003, 211, 299309.

7 D. J. Safarik and R. B. Eldridge, Ind. Eng. Chem. Res., 1998, 37, 2571-2581.

8 M. Azhin, T. Kaghazchi and M. Rahmani, J. Ind. Eng. Chem., 2008, 14, 622-638.

9 T. Ren, M. Patel and K. Blok, Energy, 2006, 31, 425-451.

10 S. J. Kim, J. P. Jung, C. H. Park and J. H. Kim, Membr. J., 2015, 25, 496-502.

11 R. Faiz and K. Li, Chem. Eng. Sci., 2012, 73, 261-284.

12 J. H. Kim, S. W. Kang and Y. S. Kang, J. Polym. Res., 2012, 19, 9753-9759.

13 S. M. Davoodi, M. Sadeghi, M. Naghsh and A. Moheb, RSC Adv., 2016, 6, 23746-23759.

14 O. Salinas, X. Ma, E. Litwiller and I. Pinnau, J. Membr. Sci., 2016, 500, 115-123.

15 B. D. Freeman, Macromolecules, 1999, 32, 375-380.

16 I. S. Chae, S. W. Kang and Y. S. Kang, RSC Adv., 2014, 4, 30156-30161.
17 X. M. Zhang, Z. H. Tu, H. Li, L. Li, Y. T. Wu and X. B. Hu, J. Membr. Sci., 2017, 527, 60-67.

18 L. A. El-Azzami and E. A. Grulke, J. Membr. Sci., 2009, 328, 15-22.

19 S. Jeong, H. Sohn and S. W. Kang, Chem. Eng. J., 2018, 333, 276-279.

20 S. W. Kang, W. Bae, J. H. Kim, J. H. Lee and Y. S. Kang, Ind. Eng. Chem. Res., 2009, 48, 8650-8654.

21 S. W. Kang and Y. S. Kang, J. Colloid Interface Sci., 2011, 353, 83-86.

22 I. S. Chae, S. W. Kang, J. Y. Park, Y. G. Lee, J. H. Lee, J. Won and Y. S. Kang, Angew. Chem., Int. Ed., 2011, 50, 2982-2985.

23 A. Luna-Triguero, J. M. Vicent-Luna, P. Gómez-Álvarez and S. Calero, J. Phys. Chem. C, 2017, 121, 3126-3132.

24 S. Bendt, M. Hovestadt, U. Böhme, C. Paula, M. Döpken, M. Hartmann and F. J. Keil, Eur. J. Inorg. Chem., 2016, 27, 4440-4449.

25 U. Böhme, B. Barth, C. Paula, A. Kuhnt, W. Schwieger, A. Mundstock, J. Caro and M. Hartmann, Langmuir, 2013, 29, 8592-8600.

26 K. Eum, C. Ma, A. Rownaghi, C. W. Jones and S. Nair, ACS Appl. Mater. Interfaces, 2016, 8, 25337-25342.

27 L. Xu, M. Rungta and W. J. Koros, J. Membr. Sci., 2011, 380, 138-147.

28 S. H. Kunjattu, V. Ashok, A. Bhaskar, K. Pandare, R. Banerjee and U. K. Kharul, J. Membr. Sci., 2018, 549, 38-45.

29 Y. H. Chu, D. Yancey, L. Xu, M. Martinez, M. Brayden and W. Koros, J. Membr. Sci., 2018, 548, 609-620.

30 M. J. Lee, M. R. Abdul Hamid, J. Lee, J. S. Kim, Y. M. Lee and H. K. Jeong, J. Membr. Sci., 2018, 559, 28-34.

31 J. Yu, C. Wang, L. Xiang, Y. Xu and Y. Pan, Chem. Eng. Sci., 2018, 179, 1-12.

32 V. F. D. Martins, A. M. Ribeiro, A. Ferreira, U. H. Lee, Y. K. Hwang, J. S. Chang, J. M. Loureiro and A. E. Rodrigues, Sep. Purif. Technol., 2015, 149, 445-456.

33 H. Jeon and S. W. Kang, Polym. Compos., 2018, DOI: 10.1002/ pc. 25082 .

34 K. W. Yoon, Y. S. Kang and S. W. Kang, J. Membr. Sci., 2016, 513, 95-100.

35 J. H. Lee, J. Hong, J. H. Kim, Y. S. Kang and S. W. Kang, Chem. Commun., 2012, 48, 5298-5300.

36 D. Ji, Y. S. Kang and S. W. Kang, Sci. Rep., 2015, 5, 1636216367. 